\title{
Caught In A Severe Thunderstorm, Fuel Is Low, Passenger Having Heart Attack, Hydraulics Are Failing, Instruments Are Iffy, And No Airport Is In Sight: Quick - As The Pilot, What Do You Do?
}

Michael Craig Budden; (E-mail: mbudden@selu.edu), Southeastern Louisiana University Connie Browning Budden, (E-mail: cbudden@selu.edu), Southeastern Louisiana University

\begin{abstract}
University administrators can take a cue from pilots. Pilots regularly face decision situations where much lies in the balance. So it is with university administrators. The department, college or university itself can be compared to an aircraft. In flight, there are times when the sun shines and winds are favorable: a comfortable flight results and the mission is accomplished. At other times, thunderstorms ravage the skies, fuel may run low, structures and people may fail, and problems arise. So it is with universities and colleges. Sometimes things are great and at other times problems arise that interfere with the institution's role and mission. It is in the parallels of flying and leading an educational institution that allows flying wisdom to be of use.
\end{abstract}

\section{INTRODUCTION}

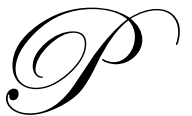

ilots, especially those who have significant flying experience have seen many a good flight, and sometimes, perhaps too often, flights and days that are not so good. Many trips are effortless and enjoyable to the point of almost routine boredom. But as everyone who has ever flown knows, there are days that are out of the ordinary that try one's nerves if not the limits of one's experience. It is in those days that pilot wisdom may be of service to university administrators as they grapple with problems and challenges they face.

As in the title of this paper, picture a plane caught in a thunderstorm with severe turbulence. A passenger is very ill, instruments are faulty, the airport is not in sight, and other problems have occurred that places the plane and some or all of those onboard at risk. Questions arise. What should the pilot do? With what should the pilot be most concerned? With so many problems facing the pilot and those onboard, the answer may seem overly simple and elementary: "Fly the airplane."

Fly the airplane. The answer is so simple and to the point that many fail to recognize it as the best course of action in an emergency situation. "Fly the airplane" as the correct course of action is a widespread recommendation and can be found in a variety of print media, internet sites, books, instructional pamphlets, etc. that are geared to pilot training. Flight schools, pilots and agencies recommend it. For instance, even NASA's Aviation Safety Reporting System" [see http://asrs.arc.nasa.gov/callback_issues/cb_315.htm] mentions it as the correct course of action to pursue given problems that may arise. Problems of all kinds may be at the cockpit door but the most important role the pilot or the university administrator may play in the midst of a storm is that of piloting the craft to the best of their ability. Sure, there are problems that may need to be faced and addressed, but failing to perform this one simple task - flying the plane - will lead to an ultimate conclusion in which none will be happy. The pilot must fly the plane despite other problems or inconsistencies that may arise. The situation may not be optimal, problems may abound, but when in 
flight, the plane must be flown. Regardless of what's happening, the first rule must be remembered - the plane must be flown.

\section{REAL-LIFE TURBULENCE - THE HEART ATTACK}

In a particular college, a professor had a major heart attack while the school term was underway. It was deemed unlikely that the professor would be able to return until the next term. Thus his classes and his students needed to be covered. The department head and dean could have spent weeks seeking a qualified replacement to be hired on a temporary basis or could simply ask existing faculty to cover the classes for which they would receive overload compensation by participating. The general policy of the school was to discourage overloads. Overloads by faculty were discouraged for various reasons including potential negative impacts on accrediting agencies' expectations, on faculty development needs, and perhaps more significantly, funds were not budgeted to cover overload compensation given that the semester was already underway.

However, due to the emergency, the term and the students could not wait. Weeks spent seeking an adjunct would create more problems and unhappy students. Turbulence in the form of uncertainty among students and their need to complete studies in a timely manner created a need that had to be addressed quickly. It was decided to pay all willing faculty overloads to complete the term of classes and to cover the advising needs of students that were negatively impacted by the ailing faculty member. Willing faculty members were asked to teach courses using the original course syllabi and to hold to expectations of material to be covered as presented the first day of classes. Faculty members willingly accepted the appointments to cover the assigned classes and the plane continued to fly. Though there was no apparent source of funds to pay the overloads when the decision was made, funding was later found and the need covered. When the plane needed to be flown, it was.

\section{REAL-LIFE TURBULENCE - THE MISSING FACULTY MEMBER}

In another incident, perhaps bizarre in some ways, a professor failed to show up for work one Monday towards the end of a semester. Classes that day were dismissed and efforts were made to contact the professor. Phone messages were left, an email was sent, and a written note placed in his mailbox. Having an every-other day teaching schedule, it was assumed he might have taken ill or had some kind of emergency but would return Tuesday or Wednesday. He didn’t.

By Thursday, word had been received via an acquaintance at another university that the professor had left the country after becoming angry and would not be returning. Upon entering the faculty member's office, the department head found that all books, files, exams, and records of every kind had been removed from the office. Only the school's computer, phone, furniture and supplies had been left behind. No student records of any kind remained. No grade books were left behind. No history of students attending was available. No performance information to assign grades was available. No progression information of any kind was available on which to evaluate and grade students. The missing faculty member coupled with lack of assessment information proved significant problems to be faced.

Two class days had already been missed at a busy time in the semester. It was decided that the department head would request his faculty to teach overloads to cover the remainder of the semester. They would be paid overload compensation on a pro rata basis. They would use the existing syllabi and students would be asked individually where they stood academically within each class. Whatever grades the students supplied were accepted. Yes, there was room for error - or mistakes - but the class had to go on. The recovery happened as planned. Competent faculty stepped in and the semester continued without problem. The semester concluded with little or no discontent on the part of students - indeed as may be surmised, many were happy with the outcome. As in the first example, classes needed to be covered. Students needed to be taught. The education process continued and students were not disrupted. The flight continued unabated. 


\section{REAL-LIFE TURBULENCE - THE LIBRARY}

In another situation, perhaps not a crisis, but one that presented a problem involved a state university's library expenditures and prioritization. The library in question purchased books as they all do during the school's fiscal year and according to the budget allotted. The library was located in a state that provided additional acquisition monies each year, using a formula that took into account the number of books acquired by the library during the previous year. The more books acquired by libraries in a given year, the more funds they were allocated during the next year to purchase books.

One year, a college requested the library acquire an online database felt to be invaluable to supporting faculty and student research. The database was quite expensive and no funds had been allocated to provide for its acquisition. The dean of the college and the dean of the library discussed the situation. To acquire the database, the number of books able to be purchased through the library's budget would decrease. That decrease in the number of books acquired would result in a substantial budget hit the next year, as the formula used to calculate the additional funds would result in less funding for the library. Since the database would be leased, the decrease in budget the next year, coupled with the on-going lease of the database would result in further budget cuts in ensuing years. The potential for the budget to feed on itself was significant and posed a problem.

A decision was reached quickly. The dean of the college committed the college's faculty to donate a minimum of 100 books annually - the estimated value of books necessary to cover the database - to the library. This donation would keep book acquisitions up and prevent future budgets from being impacted negatively. The library dean agreed to divert the funds that would have been spent purchasing books to acquire the database. The commitment for the book donation was made without prior consultation of the faculty of the college. Upon explaining the trade and its benefits to the faculty, over 200 books were immediately donated to the library on behalf of the college. The library acquired the database and faculty and students alike benefited. Future years saw faculty donating more than 100 books annually to continue to support the pact. The database was needed to develop student and faculty skill sets. It was acquired. The plane was flown.

\section{REAL-LIFE TURBULENCE - ADJUNCTS AND BUDGETS}

As any university administrator knows, personnel costs make up the bulk of an institution's budget. Personnel costs in the form of faculty compensation and benefits, staff compensation and benefits, and administrative costs all add up to the single largest category of a university budget. This large and necessary dependence on people at most institutions is the reason that mandated budget cuts hit home so quickly. One can cut travel, supplies and such to address short term needs, but the amount of such savings is usually small compared to the overall budget. In the long run, people costs are significant and difficult if not painful to decrease to cover a short run need.

Colleges and departments often are allocated funds for the acquisition of part-time adjunct faculty members. Adjuncts often fill specialty voids or are utilized to cover fluctuations in enrollment on an as-needed basis. They are also acquired as a means of addressing student needs while restraining overall faculty costs as it is usually cheaper to hire adjuncts who usually receive little or no benefits than full-time faculty members who garner benefits.

At one particular institution that was experiencing rapid growth the adjunct budget had quickly been spent expanding the number of class sections to be offered. Even after spending the budgeted amount, the need for additional class sections was apparent. The decision was made on the spot to add sections - if these new sections produced sufficient enrollment - they would pay for themselves. And they did. The sections generated enough student credit hour production (tuition) which made it worthwhile to offer the courses. Had they not, the plane would still have been flown. The move had been and would have been correct at any level. 


\section{REAL-LIFE TURBULENCE - THE STORM OF THE CENTURY AND HER SISTER}

In August 2005 Louisiana was hit with the worst natural and man-made disasters to ever hit the United States. Katrina and Rita left behind untold devastation. More than 1,000 were killed and more than 1 million displaced. Even today, more than one year later, perhaps 300,000 have not made it home. New Orleans is still a mess. The state is still recovering.

Within days of the man-made levees failing, amidst widespread power and communication outages, while chaos was still the norm, Southeastern Louisiana University, located outside of New Orleans managed to get in touch with much of its faculty and staff. The president made an informed decision to get students back into school and everyone back into their routines as quickly as possible.

Many faculty, staff and students were displaced. Over 1,000 Southeastern students could not return to complete the semester. For many others, the university was a haven. More than 1,500 students displaced from their universities in New Orleans, re-enrolled at Southeastern. State Higher Education officials and university administrators had decided fees were not to be of a concern, nor were official transcripts and other formalities normally associated with transfer students enrolling. Dorm rooms were filled to capacity - family members of students sometimes seeking shelter as well. Empty dorms that had been slated for demolition as a part of an on-going campus modernization program were temporarily reopened to provide housing for displaced faculty, staff and their families. University ancillary facilities were provided to law enforcement, military and other first-responders to use for housing and staging of recovery operations.

It could be argued that conditions were poor at best in which to operate any enterprise, let alone an institution of higher education with more than 16,000 students. New students, entering weeks after the start of the semester, required faculty to basically "start over" with their classes and play catch-up with all students. Allowances had to be made as housing, food, communication, power and other necessities were lacking or spotty for many. It was not the best of times - not even close. Still the university had to operate. The educational process had to continue. It did continue. It succeeded beyond anyone's expectations. Despite a plethora of reasons why the university should not have been able operate, it had to operate. The plane was in flight and had to be flown. And it was.

\section{SUMMARY}

Given troubling situations that often arise in an educational setting, it is not unheard of for administrators to sometimes fall prey to indecision due to the myriad decisions they must face. Dwelling on a variety of issues while the plane falls is not advantageous to anyone. Indeed, getting bogged down in a myriad of problems and allowing those problems to diminish the ability of the pilot to fly the plane can cause major problems for which extraction may prove difficult if not impossible. The primary role of the pilot parallels that of the administrator. The plane must be flown. The unit must operate.

\section{REFERENCE}

1. Callback ASRS [http://asrs.arc.nasa.gov/callback_issues/cb_315.htm]. November 19, 2006. 